\title{
Lipid peroxidation in the adrenal glands of male rats exposed to 2,3,7,8-tetrachlorodibenzo-p-dioxin (TCDD)
}

\author{
Lorelle L. Bestervelt, Douglas W. Piper, Jeff A. Pitt and \\ Walter N. Piper
}

Toxicology Program, School of Public Health, Department of Pharmacology, Medical School and Reproductive Sciences Program, The University of Michigan, Ann Arbor, MI (USA)

(Received 5 January 1993)

(Accepted 5 March 1993)

Key words: TCDD; Adrenal cytochrome P-450; Lipid peroxidation

\section{SUMMARY}

This study was performed to determine whether TCDD $(50 \mu \mathrm{g} / \mathrm{kg}$; single oral dose $)$ could induce adrenal microsomal lipid peroxidation, which might be correlated to decreased levels of cytochrome P-450 and 21-hydroxylase activity. The amount of malondialdehyde (MDA) formed was significantly higher than controls at days 1 through 5 following TCDD treatment. Microsomal cytochrome P-450 levels were depressed after lipid peroxidation at days 1,3, and 5, and 21-hydroxylase activity decreased at day 5 after TCDD treatment. This study shows that TCDD stimulates adrenal microsomal lipid peroxidation which is associated with decreased cytochrome P-450 levels and 21 -hydroxylase activity.

\section{INTRODUCTION}

Polychlorinated dibenzo-p-dioxins (PCDDs) have received increasing attention in the scientific literature over the past 20 years as toxic environmental pollutants. Most attention has focused on 2,3,7,8-tetrachlorodibenzo-p-dioxin (TCDD) which is considered to be the most toxic and extensively studied PCDD.

TCDD is a toxic and undesired by-product formed during incineration, bleaching of paper pulp and the commercial synthesis of chlorinated phenoxyacetic acid herbi- 
cides [1-3]. Widespread use of herbicides, as well as the presence of TCDD in incinerated trash and bleached paper products, has caused concern over potential human health hazards associated with the release of this chemical into the environment $[4,5]$.

Animals exposed to 2,3,7,8-tetrachlorodibenzo-p-dioxin (TCDD) typically exhibit reduced food intake and waste away in a starvation-like manner, with death occurring from 2 to 6 weeks after administration of a single, oral dose [6]. TCDD-induced hirsutism, alopecia and chloracne reported in various mammalian species suggest that adverse effects of TCDD may be mediated through alterations in endocrine function [7-11]. Anorexia, progressive weight loss and hypoglycemia suggest that this toxicant alters adrenal function [12,13]. This suggestion is given added weight by the observation of accumulation of TCDD in the adrenal gland and pathological lesions in this organ following TCDD exposure $[14,15]$. Previous studies in this laboratory have shown that exposure of rats to TCDD results in decreased adrenal 21-hydroxylase activity associated with depressed levels of microsomal cytochrome P-450 [16]. It has been shown that porcine adrenocortical microsomal cytochrome P- 450 content and 21-hydroxylase activity are very susceptible to lipid peroxidation [17]. Increases in the rate of lipid peroxidation in bovine adrenal cortex and guinea pig adrenal microsomes are associated with a decrease in the activity of adrenocortical 21-hydroxylase $[18,19]$. Thus, damage to monooxygenases may have deleterious effects on adrenocortical function, especially adrenal steroidogenesis. TCDD-induced microsomal lipid peroxidation has been demonstrated in a variety of tissues, including liver, kidney, thymus and testes [20]. The present study was undertaken to determine whether TCDD could induce microsomal lipid peroxidation in the adrenal glands of male rats and if lipid peroxidation could be correlated to decreased concentrations of adrenal microsomal cytochrome P-450 levels and 21-hydroxylase activity.

\section{MATERIALS AND METHODS}

TCDD ( $50 \mu \mathrm{g} / \mathrm{kg}$ body weight) was administered in a single oral dose to adult, male Sprague-Dawley rats (Charles River, Portage, MI; 220-240 g). Acetone/corn oil (1:2, $3.8 \mathrm{mg} / \mathrm{ml}$ ) served as the control vehicle. Rats were permitted food (Purina Rodent Chow, Ralston-Purina Co., St. Louis, MO) and water ad libitum, and were maintained on a 12 -h light/dark cycle. Rats were sacrificed $(8: 00 \mathrm{a} . \mathrm{m}$.) by decapitation and the adrenal glands were removed, trimmed of fat, and weighed. The adrenal glands

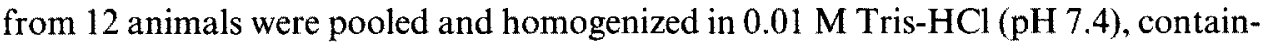
ing $0.25 \mathrm{M}$ sucrose and $0.5 \mathrm{mM} \mathrm{Na} \mathrm{EDDTA}_{2}$ (homogenization buffer) using a motordriven glass Potter-Elvehjem homogenizer and a Teflon pestle $(0.15 \mathrm{~mm}$ clearance $)$. The homogenate was centrifuged at $14000 \times g$ for $15 \mathrm{~min}$ to pellet the unbroken cells, nuclei and mitochondria. The postmitochondrial supernatant fraction was centrifuged at $105000 \times \mathrm{g}$ for $60 \mathrm{~min}$ to pellet the microsomes. The microsomal pellet was resuspended in $0.02 \mathrm{M}$ Tris- $\mathrm{HCl}(\mathrm{pH} 7.4)$. The microsomal homogenate was diluted 4 -fold with the homogenization buffer and resedimented at $105000 \times \mathrm{g}$ for $60 \mathrm{~min}$ to 
remove the EDTA and sucrose, and to minimize cytosolic contaminants. The washed microsomes were resuspended in $0.1 \mathrm{M}$ potassium phosphate ( $\mathrm{pH} 7.4$ ).

Lipid peroxidation was determined as follows: A microsomal suspension (final protein concentration of $0.4 \mathrm{mg} / \mathrm{ml}$ ) was incubated for $15 \mathrm{~min}$ with $75 \mu \mathrm{M} \mathrm{FeSO}_{4}, 0.8$ $\mathrm{mM}$ NADPH, $0.1 \mathrm{M}$ potassium phosphate ( $\mathrm{pH} 7.4$ ), in a total volume of $0.5 \mathrm{ml}$. Incubations were conducted in a metabolic shaker ( 100 oscillations per min) at $37^{\circ} \mathrm{C}$. After incubation aliquots were removed from each flask for MDA determinations and the remainder was centrifuged at $105000 \times g$ for $60 \mathrm{~min}$ to sediment the microsomal fraction. The microsomal pellets were then resuspended in $0.1^{\circ} \mathrm{M}$ potassium phosphate buffer ( $\mathrm{pH}$ 7.4), and used for cytochrome P-450 analyses and quantification of 21-hydroxylase activity.

The amount of (MDA) was determined spectrophotometrically by the thiobarbituric acid method [21,22] using an extinction coefficient of $156 \mathrm{mM}^{-1} \mathrm{~cm}^{-1}$ [23]. Butylated hydroxytoluene was added to the TBA reagent $(0.01 \%)$ to prevent nonspecific chromophore formation during boiling. Cytochrome P-450 concentrations were measured by the carbon monoxide difference spectrum $(450490 \mathrm{~nm})$ of the dithionite-reduced microsomes using an extinction coefficient of $91 \mathrm{mM}^{-1} \mathrm{~cm}^{-1}$ [24].

21-Hydroxylase enzyme activity was determined as follows: $200 \mu \mathrm{l}$ of microsomal suspension ( $50 \mu \mathrm{g}$ protein) was incubated with $500 \mu \mathrm{M}$ glucose-6-phosphate, 5 units glucose-6-phosphate dehydrogenase, $5 \mathrm{mM} \mathrm{MgCl}$, and $25 \mu \mathrm{M}(0.56 \mu \mathrm{Ci})\left[{ }^{14} \mathrm{C}\right]$ progesterone in a total volume of $0.4 \mathrm{ml}$. Incubations were conducted in a metabolic shaker at $37^{\circ} \mathrm{C}$ for $10 \mathrm{~min}$. The reaction was terminated by the addition of $1.6 \mathrm{ml}$ $\left(5^{\circ} \mathrm{C}\right)$ methanol. The deoxycorticosterone formed was isolated by thin-layer chromatography (cyclohexane/ethylacetate, 45:55 v/v), scraped from the plate, placed in $1 \mathrm{ml}$ scintillation fluid (ScintiVerse ${ }^{\mathrm{TM}}$, Fisher Scientific, Pittsburgh, PA), and quantified by counting each sample for radioactivity. Microsomal protein concentrations were determined as described by Lowry [25]. Statistical differences between mean values were analyzed by Student's $t$-test.

\section{RESULTS}

The amount of MDA formed was found to be significantly higher than controls at days 1, 2, 3 and 5 following the administration of TCDD (Fig. 1). The amount of MDA produced was increased 1.9-fold relative to controls on day 1 ; whereas at days 2, 3 and 5 the amount of MDA produced was increased 5-, 3.5- and 3.1-fold, respectively. The TCDD induced adrenal microsomal lipid peroxidation appears to be associated with a depression of adrenal microsomal cytochrome P-450 levels and adrenal microsomal 21-hydroxylase activity (Table I). Adrenal microsomal cytochrome P450 levels were depressed after lipid peroxidation to $63 \%$ of controls at day 1 ; whereas at days 3 and 5 the levels were decreased to $74 \%$ and $56 \%$ of controls, respectively. 21-Hydroxylase activity was also depressed after lipid peroxidation at day 5 to $73 \%$ of control. 


\section{DISCUSSION}

The data provided in Figure 1 show that TCDD is capable of stimulating lipid peroxidation in rat adrenal microsomes. TCDD-induced microsomal lipid peroxidation has been demonstrated in a variety of other tissues [20], but never before in the adrenal gland. These results indicate that TCDD causes early increases in adrenal microsomal lipid peroxidation that are associated with depressed levels of adrenal microsomal cytochrome P-450 concentrations and decreased activity of adrenal microsomal 21-hydroxylase.

Progressive depression of microsomal cytochrome P-450 from days 2-5 is consistent with its reported half-life of 2.9 days [26]. The activity of microsomal 21-hydroxylase was not depressed to the same extent as was microsomal cytochrome P-450. This observation may be due to the presence of additional microsomal cytochrome $\mathrm{P}-450$ in the adrenal gland. For example, it has been reported that $17 \alpha$-hydroxylase is present in the rat adrenal. However, this $17 \alpha$-hydroxylase does not function in the rat corticosteroid biosynthetic pathway except when induced by estrogen [27]. Also, the half-life of rat microsomal 21-hydroxylase (4.5 days) is greater that that for microsomal cytochrome P-450 (2.9 days), suggesting that another microsomal cytochrome P-450 exists in the rat adrenal [26]. Kaufmann et al. [28] and Diedrichsen et al. [29] suggest that in the rat two alternate pathways for the formation of 21-hydroxylated steroids exist: (i) the 5-ene substrate pathway, and (ii) the 3-keto-4-ene substrate pathway. In fact, there is evidence that two 21-hydroxylase isozymes exist in the rat adrenal gland. Both 21-hydroxypregnenolone and 17,21-dihydroxypregnenolone have been recovered in rat adrenal tissue indicating that both pregnenolone and 17-hydroxyprogesterone can serve as substrates for rat adrenal 21-hydroxylase $[28,29]$.

Increases in lipid peroxidation have been shown to promote the degradation of

\section{TABLE I}

RELATIONSHIP OF ADRENAL MICROSOMAL LIPID PEROXIDATION TO DEPRESSED CYTOCHROME P-450 CONTENT AND 21-HYDROXYLASE ACTIVITY

\begin{tabular}{llll}
\hline Day & $\begin{array}{l}\text { Lipid peroxidation } \\
\% \text { control }\end{array}$ & $\begin{array}{l}\text { P-450 } \\
\% \text { control }\end{array}$ & $\begin{array}{l}21-\mathrm{OH} \\
\% \text { control }\end{array}$ \\
\hline 1 & $191 \pm 30^{*}$ & - & - \\
2 & $500 \pm 28^{*}$ & $63 \pm 2^{*}$ & $88 \pm 4$ \\
3 & $272 \pm 35^{*}$ & $74 \pm 7^{*}$ & $83 \pm 5$ \\
5 & $350 \pm 31^{*}$ & $56 \pm 7^{*}$ & $73 \pm 2^{*}$ \\
\hline
\end{tabular}

Rats were given a single oral dose of TCDD $(50 \mu \mathrm{g} / \mathrm{kg})$ at day 0 . Each value is expressed as the mean percent of control $\pm \mathrm{SE}, n=36,{ }^{*}$ indicates a significant difference $(P<0.05)$ between TCDD-treated and control rats. The mean control values for lipid peroxidation, cytochrome P-450 and 21-hydroxylase were $0.024 \pm 0.004 \mathrm{nmol}$ malondialdehyde $/ \mathrm{mg} / \mathrm{min}, 0.409 \pm 0.008 \mathrm{nmol} / \mathrm{mg}$, and $4.29 \pm 0.37 \mathrm{nmol}$ deoxycorticosterone/mg/min, respectively. 


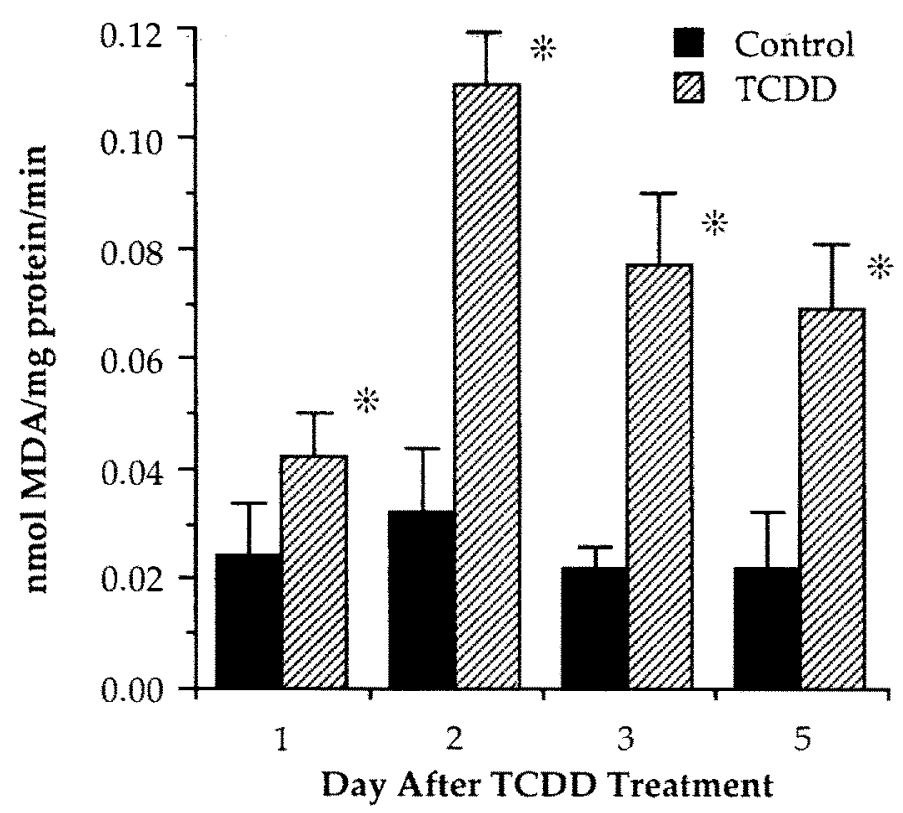

Fig. 1. Effects of a single oral dose of TCDD $(50 \mu \mathrm{g} / \mathrm{kg})$ on male rat adrenal microsomal lipid peroxidation. Each value is expressed as the mean $\pm \mathrm{SE}, n=12$. '*' indicates a significant difference $(P<0.05)$ between TCDD-treated and control rats.

microsomal cytochrome levels and loss of 21 -hydroxylase activity $[18,19]$. It is possible that the early increases of lipid peroxidation in rat adrenal microsomes are associated with the decline of microsomal cytochrome P-450 levels and 21-hydroxylase activity following TCDD exposure. Since 21 -hydroxylase is microsomal cytochrome P.450 dependent [30], it is possible that TCDD induced lipid peroxidation could facilitate decreased adrenal corticosteroid biosynthesis by the adrenal cortex. Blood concentrations of corticosterone (the adrenal steroid predominant in the rat) have been reported to be depressed by TCDD exposure [31]. Ultimately, TCDD-induced lipid peroxidation could interfere with adrenal corticosteroid biosynthesis and depress blood levels of corticosteroids.

\section{ACKNOWLEDGEMENTS}

This research was supported in part by NIH Grants ES-02423, P 30 HD-18258, and T 32 ES-07062. 


\section{REFERENCES}

1 Bumb, R.R., Crummett, W.B., Cutie, S.S., Gledhill, J.R., Hummel, R.H., Kagel, R.O., Lamparski, L.L., Luoma, E.V., Miller, D.L., Nestrick, T.J., Shadoff, L.A., Stehlean, R.H. and Woods, J.S. (1980) The trace chemistries of fire: A source of chlorinated dioxins. Science 210, 385-390.

2 Hutzinger, O., Blumich, M.J., Berg, M.V.D. and Olie, K. (1985) Sources and fate of PCDDs and PCDFs: An overview. Chemosphere 14, 581-600.

3 Olson, J.R., Bellin, J.S. and Barnes, D.G. (1989) Reexamination of data used for establishing toxicity equivalence factors (TEFS) for chlorinated dibenzo-p-dioxins and dibenzofurans (CDDS and CDFS). Chemosphere 18, 371-381.

4 Reggiani, G. (1981) Toxicology of 2,3,7,8-tetrachlorodibenzo-p-dioxin (TCDD): Short Review of its formation, occurrence, toxicology, and kinetics, discussing human health effects, safety measures, and disposal. Regul. Toxicol. Pharmacol. 1, 211-243.

5 Miller, G.C. and Zepp, R.G. (1987) 2,3,7,8-Tetrachlorodibenzo-p-dioxin: environmental chemistry. In: J.H. Exner (Ed.), Solving Hazardous Waste Problems, American Chemical Society, Washington, DC, pp. 82-93.

6 Schwetz, B.A., Norris, J.M, Sparschu, G.L., Rowe, V.K., Gehring, P.J., Emerson, J.L. and Gerbig, C.G. (1973) Toxicology of chlorinated dibenzo-p-dioxins. Environ. Health Perspect. 5, 87-99.

7 Betty, P.W., Vaughn, W.K. and Neal, R.A. (1978) Effect of alteration of rat hepatic mixed-function oxidase (MFO) activity on the toxicity of 2,3,7,8-tetrachlorodibenzo-p-dioxin (TCDD). Toxicol. Appl. Pharmacol. 45, 513-519.

8 Bleiber, J., Wallen, M., Brodkin, R. and Applebaum, I. (1964) Industrially acquired porphyria. Arch. Dermatol. 89, 793-797.

9 Poland, A., Smith, D., Metter, G. and Possick, S. (1971) A health survey of workers in a 2,4-D and 2,4,5-T plant with special attention to chloracne, porphyria cutanea tarda and psychologic parameters. Arch. Environ. Health 22, 316-327.

10 Allen, J.R. and Carstens, L.A. (1967) Light and electron microscopic observations in Mucaca mulatta monkeys fed toxic fat. Am. J. Vet. Res. 28, 1513-1526.

11 DiBartolomeis, M.J., Moore, R.W., Peterson, R.E. and Jefcoate, C.R. (1986) Hypercholesterolemia and the regulation of adrenal steroidogenesis in 2,3,7,8-tetrachlorodibenzo-p-dioxin treated rats. Toxicol. Appl. Pharmacol. 85, 313-323.

12 Harris, M.W., Moore, J.A., Vos, J.G. and Gupta, B.N. (1973) General biological effects of TCDD in laboratory animals. Environ. Health Perspect. 5, 101-109.

13 Gasiewicz, T.A., Holscher, M.A. and Neal, R.A. (1980) The effect of total parental nutrition on the toxicity of 2,3,7,8-tetrachlorodibenzo-p-dioxin in the rat. Toxicol. Appl. Pharmacol. 54, 459-488.

14 Piper, W.N., Rose, J.Q. and Gehring, P.J. (1973) Excretion and tissue distribution of 2,3,7,8-tetrachlorodibenzo-p-dioxin in the rat. Environ. Ilealth Perspect. 5, 241-244.

15 Gasiewicz, T.A. and Neal, R.A. (1979) 2,3,7,8-Tetrachlorodibenzo-p-dioxin tissue distribution, excretion, and effects on clinical chemical parameters in guinea pigs. Toxicol. Appl. Pharmacol. 51, 329-339.

16 Mehus, C.A. and Piper, W.N. (1986) Decreased rat adrenal 21-hydroxylase associated with decreased adrenal microsomal cytochrome P-450 after exposure to 2,3,7,8-tetrachlorodibenzo- $p$-dioxin. Biochem. Pharmacol. 24, 4359-4362.

17 Imataka, H., Suzuki, K. and Tamaoki, B. (1985) Effect of $\mathrm{Fe}^{2+}$-induced lipid peroxidation upon microsomal steroidogenic enzyme activities of porcine adrenal cortex. Biochem. Biophys. Res. Commun. 128, $657-663$.

18 Kitabaci, A.E. (1967) Inhibition of steroid C-21 hydroxylase by ascorbate: alterations of microsomal lipids in beef adrenal cortex. Steroids 10, 567-576.

19 Brogan III, W.C., Miles, P.R. and Colby, H.D. (1983) Effects of lipid peroxidation on adrenal microsomal monoxygenases. Biochim. Biophys. Acta 758, 114-120.

20 Al-Bayati, Z.A.F., Murray, W.J. and Stohs, S.J. (1987) 2,3,7,8-Tetrachlorodibenzo-p-dioxin induced 
lipid peroxidation in hepatic and extra hepatic tissues of male and female rats. Arch. Environ. Contam. Toxicol. 16, 159-166.

21 Asakawa, T. and Matsushita, S. (1979) Coloring conditions of thiobarbituric acid test for detecting lipid hydroperoxides. Lipids 15, 137-140.

22 Dahle, L.K., Hill, E.H., and Holman, R.T. (1962) The thiobarbituric acid reaction and the autoxidations of polyunsaturated fatty acid methyl esters. Arch. Biochem. Biophys. 98, 253-261.

23 Kornburst, D.J. and Mavis, R.D. (1980) Microsomal lipid peroxidation. I. Characterization of the role of iron and NADPH. Molec. Pharmacol. 17, 400-407.

24 Omura, T. and Sato, R. (1964) The carbon monoxide binding pigment of liver microsomes. I. Evidence for its hemoprotein nature. J. Biol. Chem. 239, 2370-2378.

25 Lowry, O.H., Rosebrough, N.J., Farr, W.L. and Randall, R.J. (1951) Protein measurement with folin phenol reagent. J. Biol. Chem. 193, 265-275.

26 Purvis, J.L., Canick, J.A., Mason, J.I., Estabrook, R.W. and McCarthy, J.L. (1973) Lifetime of adrenal cytochrome P-450 as influenced by ACTH. Ann. NY Acad. Sci. 212, 319-343.

27 Johnson, D.C. (1979) Steroid 17 $\alpha$-hydroxylase of the rat adrenal. J. Steroid Biochem. 10, 397-400.

28 Kaufmann, S.H., Sinterhauf, K., Diedrichsen, G. and Lommer, D. (1979) Biosynthesis and transformation of 20a, 21-dihydroxycholesterol by rat adrenal preparations. J. Steroid Biochem. 10, 641-646.

29 Diedrichsen, G., Sinterhauf, K., Wolff, H.P. and Lommer, D. (1978) Indications for the existence of alternative pathways of steroid synthesis via 21 -hydroxypregnenolone in the rat adrenal cortex. $J$. Steroid Biochem. 9, 5962 .

30 Simpson, E.R. and Mason, J.I. (1976) Molecular aspects of the biosynthesis of adrenal steroids. Pharmacol. Ther. B. 2, 239-369.

31 Balk, J.L. and Piper, W.N. (1984) Altered blood levels of corticosteroids in the rat after exposure to 2,3,7,8-tetrachlorodibenzo-p-dioxin. Biochem. Pharmacol. 33, 2531-2534. 